\title{
Input Organization of Multifunctional Motion-Sensitive Neurons in the Blowfly
}

\author{
Karl Farrow, Juergen Haag, and Alexander Borst \\ Department of Systems and Computational Neurobiology, Max-Plank-Institute of Neurobiology, 82152 Martinsried, Germany
}

Flies rely heavily on visual motion cues for course control. This is mediated by a small set of motion-sensitive neurons called lobula plate tangential cells. A single class of these, the centrifugal horizontal $(\mathrm{CH})$ neurons, play an important role in two pathways: figure-ground discrimination and flow-field selectivity. As was recently found, the dendrites of $\mathrm{CH}$ cells are electrically coupled with the dendritic tree of another class of neurons sensitive to horizontal image motion, the horizontal system (HS) cells. However, whether motion information arrives independently at both of these cells or is passed from one to the other is not known. Here, we examine the ipsilateral input circuitry to $\mathrm{HS}$ and $\mathrm{CH}$ neurons by selective laser ablation of individual interneurons. We find that the response of $\mathrm{CH}$ neurons to motion presented in front of the ipsilateral eye is entirely abolished after ablation of HS cells. In contrast, the motion response of HS cells persists after the ablation of $\mathrm{CH}$ cells. We conclude that $\mathrm{HS}$ cells receive direct motion input from local motion elements, whereas $\mathrm{CH}$ cells do not; their motion response is driven by HS cells. This connection scheme is discussed with reference to how the dendritic networks involved in figure-ground detection and flow-field selectivity might operate.

Key words: insect; blowfly; laser ablation; electrophysiology; motion detection; dendritic processing; vision

\section{Introduction}

Animals use the continuously moving retinal images during locomotion to guide their behavior. These optic flow patterns can indicate cues about self-motion (flow-field selectivity; e.g., rotation vs translation) as well as that of objects (figure-ground discrimination). Extracting this information from the activity profile of the array of photoreceptors involves different computational tasks. Flow-field selectivity requires the integration of information from different areas of the visual world, whereas discriminating objects from an extended background involves calculating the relative motion between the two.

In the blowfly, these tasks are both performed in the lobula plate. The lobula plate is a retinotopically organized, layered neuropile in the optic lobe. It contains the extensive dendritic trees of $\sim 60$ individually identifiable motion-sensitive neurons called lobula plate tangential cells (Hausen et al., 1980; Hausen, 1982, 1984; Hengstenberg et al., 1982; Borst and Haag, 1996; Haag and Borst, 2001). Their output conveys visual motion information that is used to guide locomotion (Heisenberg et al., 1978; Geiger and Nässel, 1981; Hausen and Wehrhahn, 1990). The response of tangential cells to motion stimuli presented in front of the ipsilateral eye is thought to result from spatially pooling the output of many thousands of retinotopically organized local motionsensitive elements. This allows these cells to integrate information over a large spatial area and forms the basis for many of the

\footnotetext{
Received July 8, 2003; revised Aug. 13, 2003; accepted Sept. 2, 2003.

We thank Renate Gleich for helping with some of the experiments and Hermann Cuntz for critically reading this manuscript.

Correspondence should be addressed to Dr. Alexander Borst, Director, Department of Systems and Computational Neurobiology, Max-Planck-Institute of Neurobiology, Am Klopferspitz 18a, 82152 Martinsried, Germany. Copyright $\odot 2003$ Society for Neuroscience $\quad$ 0270-6474/03/239805-07\$15.00/0
}

response properties of tangential cells, including optic flow processing (Krapp and Hengstenberg, 1996; Krapp et al., 1998), directional selectivity (Egelhaaf et al., 1989; Single and Borst, 1998), and gain control (Borst et al., 1995; Single et al., 1997). However, other studies have demonstrated the importance of network interactions between tangential cells within a single lobula plate for their visual response properties (Haag and Borst, 2001; Haag and Borst, 2002; Haag and Borst, 2003; Warzecha et al., 1993). A class of neurons central to many of these network connections is the centrifugal horizontal $(\mathrm{CH})$ cells.

$\mathrm{CH}$ cells possess GABAergic output synapses that are spread across their extensive lobula plate aborization (Meyer et al., 1986; Gauck et al., 1997). This inhibitory output is involved in separate computations that contribute to the detection of objects, via figure detection (FD) cells (Egelhaaf, 1985; Warzecha et al., 1993), and flow-field selectivity, via $\mathrm{H} 1$ and $\mathrm{H} 2$ neurons (Haag and Borst, 2001). These dendritic aborizations also act as an input (Egelhaaf et al., 1993; Gauck and Borst, 1999; Borst and Haag, 2002; Haag and Borst, 2002). One of the inputs to CH cells occurs via an electrical coupling with the overlapping dendritic trees of horizontal system (HS) neurons (Haag and Borst, 2002).

HS and $\mathrm{CH}$ neurons are selectively activated by front-to-back motion presented in front of the ipsilateral eye that elicits a graded depolarization of the membrane potential. In each brain hemisphere, there are three HS and two $\mathrm{CH}$ neurons. The northern (HSN), equatorial (HSE), and southern (HSS) HS cells view the top, middle, and bottom thirds of the visual field, respectively. In a similar way, the dorsal $(\mathrm{dCH})$ and ventral $(\mathrm{vCH}) \mathrm{CH}$ cells have their receptive field in the top and bottom half of the visual hemisphere. During spatially restricted motion stimulation, local calcium accumulation occurs in the dendritic trees of both HS and $\mathrm{CH}$ cells (Borst and Egelhaaf, 1992; Egelhaaf et al., 1993; 
Duerr and Egelhaaf, 1999; Haag and Borst, 2002). Hence, local motion elements must either synapse directly on the dendritic trees of HS and $\mathrm{CH}$ cells or local motion information is passed between these neurons via an electrical coupling of their dendritic trees (Haag and Borst, 2002). The direct local motion input of HS neurons may, in part, arrive via chemical synaptic input from columnar T4 cells located in the medulla (Strausfeld and Lee, 1991). Chemical input synapses have also been found on the dendritic tree of $\mathrm{CH}$ cells (Gauck et al., 1997). However, whether these synapses form the input pathway for local motion elements is not known. The experimental data available at present lead to three possible input schemes, shown in Figure 1: (1) both $\mathrm{CH}$ and HS cells receive input from local motion elements and each other (Fig. 1A); or (2) the motion response of $\mathrm{CH}$ cells is attributable entirely to input from HS cells (Fig. $1 \mathrm{~B}$ ); or (3) $\mathrm{CH}$ cells drive the response of HS cells (Fig. 1C). We used selective ablation of single neurons to demonstrate that $\mathrm{CH}$ cells receive their ipsilateral motion input exclusively via $\mathrm{HS}$ neurons and HS cells respond independently of $\mathrm{CH}$ cell input.

\section{Materials and Methods}

Animal preparation. Female, 1- to 5-d-old blowflies (Calliphora vicina) were briefly anesthetized with $\mathrm{CO}_{2}$ and mounted ventral side up with wax on a small plate of glass. The head capsule was opened from behind; the trachea and air sacs that normally cover the lobula plate were removed. The head capsule was filled with Ringer's solution. To minimize movements of the brain, the esophagus and proboscis of the animal were cut away, after which the gut was pulled out. Also, the antennae were removed, and the antennal muscles were cut. To further limit each fly's movements, flight muscles and abdominal regions were waxed.

Electrical recording. Glass electrodes were pulled on a Brown-Flaming micropipette puller (P-97) using thin-wall glass capillaries with an outer diameter of $1 \mathrm{~mm}$ (Science Products $\mathrm{GmbH}$, Hofheimer, Germany). The tip of the electrode was filled with either $10 \mathrm{~mm}$ Alexa 568 (Alexa Fluor 568 hydrazide; Molecular Probes, Eugene, OR) or 6-carboxy-fluorescein (fluorescein; Molecular Probes). Alexa 568 and 6-carboxy-fluorescein fluoresce as red and green, respectively, allowing us to identify more than one cell at time. The shaft of the electrode was filled with $2 \mathrm{M}$ KAc plus 0.5 $\mathrm{M} \mathrm{KCl}$. Electrodes had resistances of either $10-15 \mathrm{M} \Omega$ or $15-20 \mathrm{M} \Omega$ for Alexa-filled and 6-carboxy-fluorescein-filled electrodes, respectively. Recorded signals were amplified using an SEL10 amplifier (NPI Electronic, Tamm, Germany). All recordings were made in the axons of the neurons. The output signal of the amplifier was passed to a Pentium III personal computer via a 12 bit analog-to-digital converter (DAS-1602; ComputerBoards, Inc. Middleboro, MA) at a sampling rate of either 1 or $5 \mathrm{kHz}$.

Visual stimulation. Visual stimuli were presented on a Tektronix 608 monitor (width, $10 \mathrm{~cm}$; height, $13 \mathrm{~cm}$ ). The monitor was located $6 \mathrm{~cm}$ in front of the fly. The center of the screen was at $0^{\circ}$ elevation from the equator of the fly's eyes and orientated $55^{\circ}$ lateral from the midline. As seen by the fly, the monitor had a horizontal angular extent of $79^{\circ}$ and a vertical extent of $94^{\circ}$. The pattern consisted of a square wave grating with a spatial wavelength of $41^{\circ}$, produced by an image synthesizer (Picasso; Innisfree Inc.) at a frame rate of $200 \mathrm{~Hz}$. The image synthesizer was controlled by a Pentium III personal computer via a DAS16/12 board (Computer Boards, Inc.). The pattern moved at a temporal frequency of $1.7 \mathrm{~Hz}$, which is defined as the angular velocity of the pattern divided by its spatial wavelength. The pattern contrast was $96 \%$. The mean luminance of the pattern amounted to $2.5 \mathrm{~cd} / \mathrm{m}^{2}$. The stimulation and acquisition software was written in Delphi (Borland).

Laser ablation. The selective ablation of single neurons was performed by laser illumination of the lobula plate with a $15 \mathrm{~mW}$ blue $(488 \mathrm{~nm})$ laser
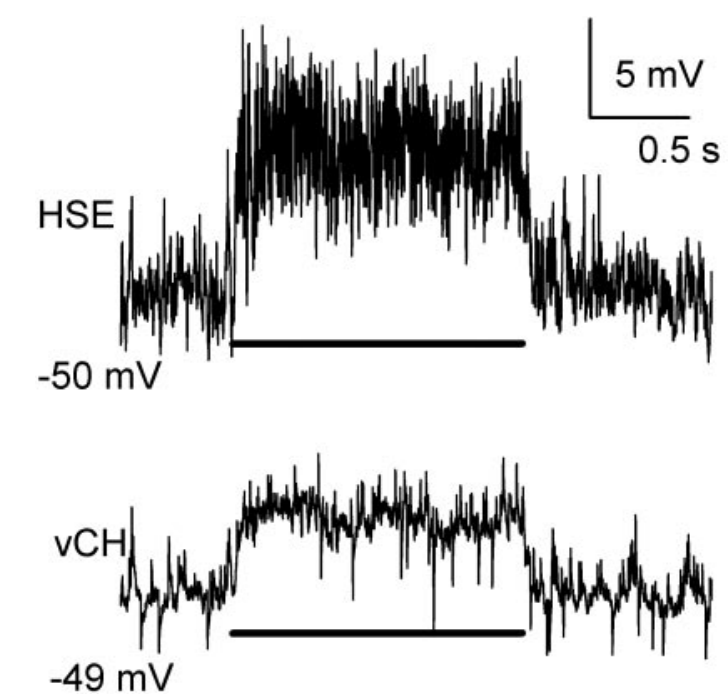

Figure 2. Response of simultaneously recorded HSE and vCH cells to an ipsilaterally presented motion stimulus in the PD (i.e., from front to back). Both neurons responded with a graded membrane shift of either $7 \mathrm{mV}$ (HSE) or $4 \mathrm{mV}$ (vCH) superimposed by EPSPs. In addition, the HSE cell response appears nosier because of the active properties present in HS cells. The bar underneath the response traces indicates the stimulus period.

(163-E11; Spectra Physics) for $120 \mathrm{sec}$. The cell to be ablated was filled with a saturated solution of 6-carboxy-fluorescein in $1 \mathrm{M}$ potassium acetate ( -2 to $-10 \mathrm{nA} ; 1-15 \mathrm{~min})$. The neuron to be recorded was filled with Alexa 568. This allowed for the selective ablation of the fluoresceinfilled neuron because, unlike 6-carboxy-fluorescein, Alexa 568 is only weakly excited by blue light $(488 \mathrm{~nm})$ and, therefore, is not toxic to the neuron while it fluoresces. This procedure was first developed for singlecell ablation in the lobster (Miller and Selverston, 1979; Selverston and Miller, 1980; Selverston et al., 1985) and was later successfully applied in the auditory system of crickets (Jacobs and Miller, 1985; Selverston et al., 1985) as well as the visual system of the blowfly (Warzecha et al., 1993).

\section{Results}

HS and $\mathrm{CH}$ neurons not only share many visual response properties but are also electrically connected (Haag and Borst, 2002). Each $\mathrm{CH}$ neuron has a dendritic field that overlaps with two of the three HS neurons. dCH cells receive input from HSN and HSE neurons, whereas vCH cells are connected to HSE and HSS neurons via their overlapping dendritic trees (Haag and Borst, 2002). The responses of $\mathrm{HS}$ and $\mathrm{CH}$ neurons to preferred direction (PD) motion presented in front of the ipsilateral eye are similar. Each responds with a graded shift in membrane potential (Eckert and Dvorak, 1983). In Figure 2, the response of an HSE and $\mathrm{vCH}$ neuron to ipsilaterally presented PD motion is shown. Here, a 
square wave grating, with its vertical extent restricted to the receptive field of the HSE neuron, was moved in the PD during which the neurons responded with a graded shift in average membrane potential of $7 \mathrm{mV}$ (HSE) or $4 \mathrm{mV}$ ( $\mathrm{vCH}$ ). In addition, the HS neuron also produced small action potential-like events, called spikelets (Hengstenberg, 1977; Haag and Borst, 1996). The high-frequency events seen in the vCH trace are EPSPs caused by input from contralateral $\mathrm{H} 1$ and $\mathrm{H} 2$ cells. To investigate whether the response of $\mathrm{CH}$ neurons is solely attributable to input from HS neurons or a combination of HS input and parallel input from columnar elements, a single HS neuron was selectively ablated while a $\mathrm{CH}$ neuron, with an overlapping dendritic field, located in the same hemisphere was recorded by means of intracellular electrodes.

\section{Ablation assessment}

To assess the effectiveness and specificity of our ablation technique, the visual response to PD motion, membrane potential, and input resistance of a neuron, filled with either 6-carboxyfluorescein or Alexa 568, was measured before and after consecutive exposure of the neuron to laser illumination ( $15 \mathrm{~mW}, 488$ $\mathrm{nm}$ ) for periods of $30 \mathrm{sec}$. Between exposure periods, we waited 1 min before testing the input resistance and visual response of the neuron. We found that after four epochs of laser exposure (i.e., a total of $120 \mathrm{sec}$ ), the input resistance of an HSE neuron filled with 6-carboxy-fluorescein was reduced from $\sim 4$ to $1 \mathrm{M} \Omega$ (Fig. $3 A$, black line), whereas its resting membrane potential went from -49 to $-15 \mathrm{mV}$ (Fig. $3 B$, black line). In addition, the visual response of the HSE neuron fell from 3.5 to $0.2 \mathrm{mV}$ (Fig. $3 C$, black line). Similar results were found in an HSS and dCH neuron.

When a dCH neuron was filled with Alexa 568, instead of fluorescein, the input resistance, visual response, and resting membrane potential remained constant for as long as we were able to hold the neuron (Fig. 3, gray line). This was also true in one other $\mathrm{CH}$ neuron tested. This demonstrates that we are able to selectively ablate single neurons.

\section{HS ablations}

In Figure $4 A$, one can see the average response of a $\mathrm{vCH}$ neuron to a PD motion stimulus both before (dark line) and after (light gray line) the ablation of an HSE neuron. Here, the HSE was filled with 6-carboxy-fluorescein and the vCH with Alexa 568. The average response of the $\mathrm{vCH}$ neuron to $\mathrm{PD}$ motion was $3.0 \pm 0.2$ $\mathrm{mV}$ (mean $\pm \mathrm{SEM}$ ) in the intact animal, whereas this response was reduced to $0.4 \pm 0.1 \mathrm{mV}$ after the selective ablation of the HSE cell (Fig. 4B, third column). The visual stimulus was restricted to the receptive field of the HSE neuron and had a vertical extent of $14.25^{\circ}$. After the ablation, the response of the $\mathrm{vCH}$ neuron has not completely disappeared, which may be caused by a residual response of the HSS neuron. Similar results were found in three other experiments (Fig. $4 B$ ). In Figure $4 B$, one can see the response of $\mathrm{vCH}$ cells before and after the ablation of either the HSE or HSS cell, as well as the effect of the ablation of an HSN cell in the response of a $\mathrm{dCH}$ cell. On average, the response of the $\mathrm{CH}$ neurons fell to $11 \pm 4 \%$ ( \pm SEM; $n=4$ ) of the preablation response (Fig. $4 C$ ). The average response fell from $1.69 \pm 0.56$ to $0.17 \pm 0.09 \mathrm{mV}$ (mean $\pm \mathrm{SEM} ; n=4$; Fig. $4 C)$.

\section{$\mathrm{CH}$ ablations}

To test whether HS cells are driven directly by local motion elements or via input from $\mathrm{CH}$ cells, HS cells were recorded both before and after the ablation of a single $\mathrm{CH}$ neuron. In Figure $5 \mathrm{~A}$, the average response of an HSN cell is shown both before (black
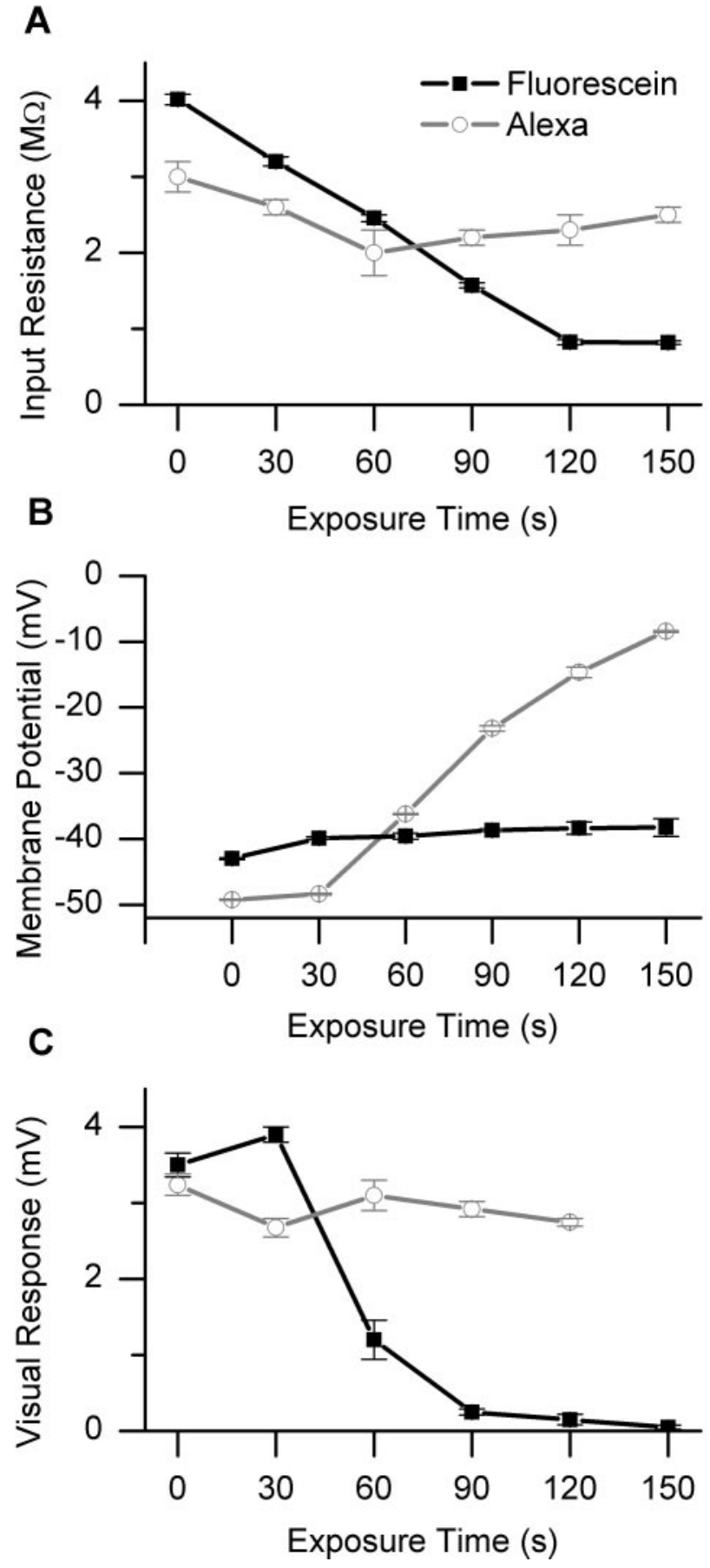

Figure 3. Ablation assessment. Response of an HSE neuron, filled with fluorescein (black line), or a dCH neuron, filled with Alexa 568 (gray line), after illumination with a 15 $\mathrm{mW}$ laser for periods of $30 \mathrm{sec}$. These cells were recorded separately in different flies. The input resistance $(A)$, membrane potential $(B)$, and visual response to ipsilaterally presented PD motion $(C)$ of each neuron was measured 1 min after each epoch of laser illumination. Each point is the mean \pm SEM.

line) and after (light gray line) the selective ablation of a $\mathrm{dCH}$ neuron. Here, the $\mathrm{dCH}$ was filled with 6-carboxy-fluorescein and the HSN with Alexa 568. The visual stimulus was again restricted to $14.25^{\circ}$. After the ablation of the $\mathrm{dCH}$ neuron, the response of the HSN neuron did not seem to change. Its response before the ablation of the $\mathrm{dCH}$ neuron was $2.67 \pm 0.03 \mathrm{mV}$, whereas after the ablation it was $2.75 \pm 0.03 \mathrm{mV}$ (mean \pm SEM). Figure $5 B$ shows the response of an HSE cell both before and after the abla- 
A
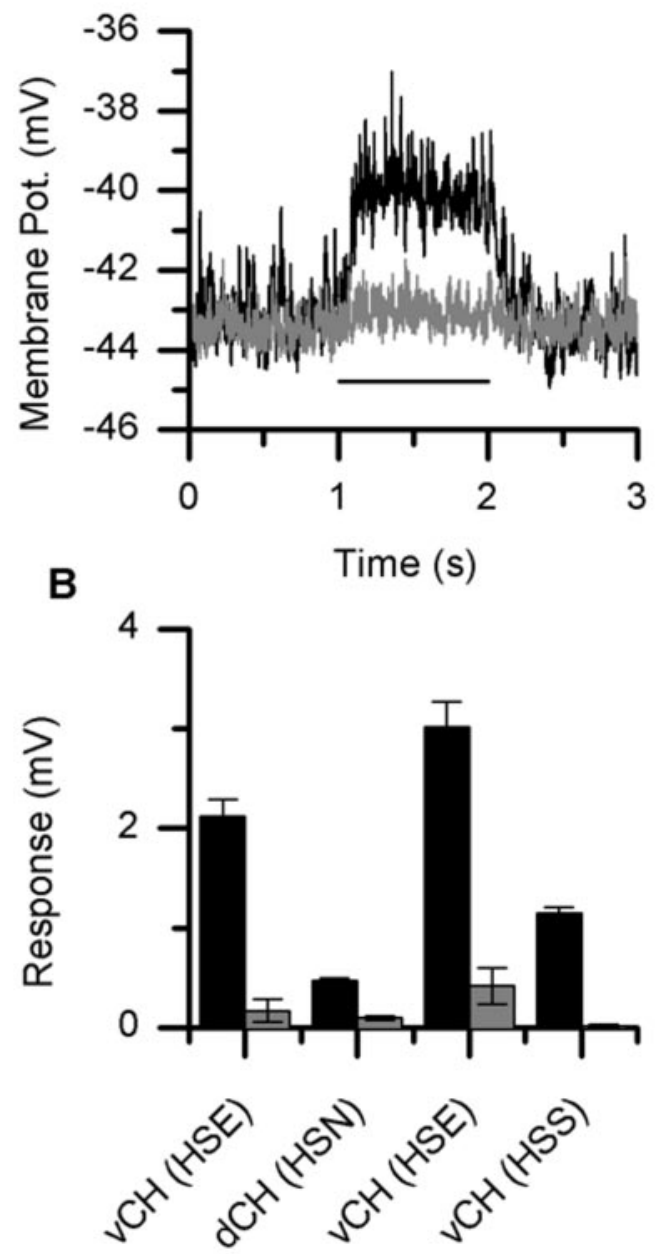

C
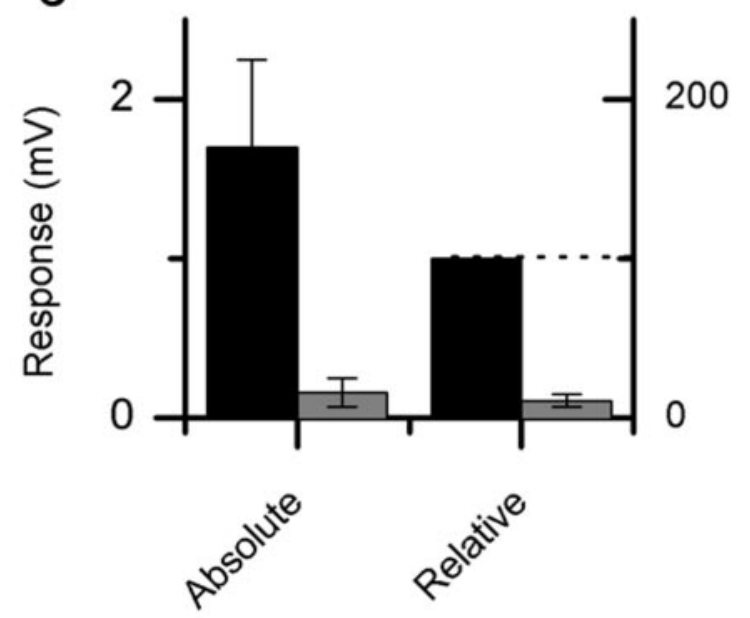

Figure 4. HS cell ablations. A, Average response of a vCH neuron to PD motion both before (black line) and after (gray line) the selective ablation of an HSE neuron. The bar underneath the response traces indicates the stimulus period. The response dropped from $3.01 \pm 0.15$ to $0.42 \pm 0.1 \mathrm{mV}$ (mean $\pm \mathrm{SEM}$ ). $B$, Average response of $\mathrm{CH}$ neurons before and after the selective ablation of single $\mathrm{HS}$ neurons. There are two examples of a $\mathrm{vCH}$ neuron before and after the ablation of an HSE neuron (columns 1 and 3). One example of a vCH cell before and after an HSS neuron ablation (column 4). Also shown is the average response of a $\mathrm{dCH}$ cell after the ablation of an HSN neuron (column 2). C, The average response of these four neurons went from $1.69 \pm$ 0.56 to $0.17 \pm 0.09 \mathrm{mV}$ (mean \pm SEM) after the ablation of a single HS neuron, which corresponds to a reduction of $89 \pm 4 \%$.

\section{A}
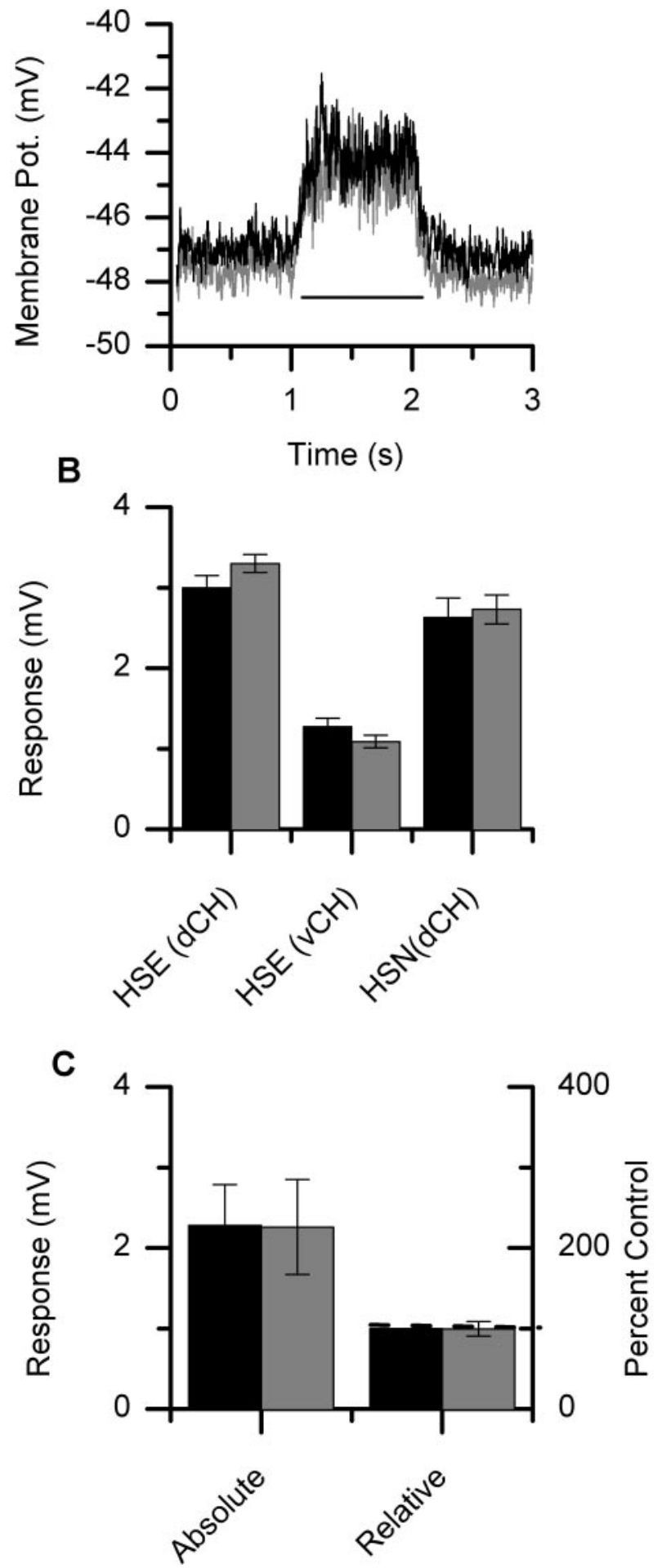

Figure 5. CH cell ablations. A, Average response of an HSN neuron both before (black line) and after (light gray line) the selective ablation of a $\mathrm{dCH}$ neuron. The bar underneath the response traces indicates the stimulus period. The response changed from $2.63 \pm 0.03$ to $2.73 \pm 0.03 \mathrm{mV}$ (mean $\pm \mathrm{SEM}$ ) after ablating the $\mathrm{dCH}$ neuron. $B$, Average response of $\mathrm{HS}$ neurons before and after the selective ablation of single $\mathrm{CH}$ neurons. Two examples of an HSE cell are shown with the ablation of either a dCH cell (column 1) or a vCH cell (column 2). In addition, the mean response of an $\mathrm{HSN}$ cell is shown both before and after the ablation of a $\mathrm{dCH}$ cell (column 3). The error bars represent the SE of the mean. C, The average response of these three neurons before the ablation was a graded shift in membrane potential of $2.28 \pm 0.51$ (mean \pm SEM). The response after the selective ablation of a $\mathrm{CH}$ neuron was $2.26 \pm 0.59$ (mean \pm SEM), which responds to a decrease of only $0.66 \pm 10 \%$. 
tion of either a dCH or vCH cell. Also shown is the affect of ablating a dCH cell on the response of an HSN cell. In Figure 5C, the average response (mean \pm SEM) of three HS cells to ipsilaterally presented PD motion is shown both before $(2.28 \pm 0.51$ $\mathrm{mV})$ and after $(2.26 \pm 0.59 \mathrm{mV})$ the ablation of a single $\mathrm{CH}$ neuron. This is a change of only $0.66 \%$ as compared with a reduction of $89 \%$ in the response of $\mathrm{CH}$ neurons after the ablation of HS neurons. The response of HS neurons seems to be independent of input from $\mathrm{CH}$ cells.

An additional experiment demonstrates the spatial relationship between these neurons (data not shown). An HSN neuron, filled with fluorescein, was ablated while a $\mathrm{vCH}$ neuron filled with Alexa 568 was recorded. These two neurons are not supposed to be connected because the dendritic trees of these neurons do not overlap. The response of the $\mathrm{vCH}$ neuron in its receptive field was $2.66 \pm 0.1$ in the intact animal and $2.43 \pm 0.2$ after the ablation of HSN. This experiment demonstrates that neurons that do not have overlapping dendritic trees are not connected.

Taken together, the set of experiments reported above speak strongly for the idea that HS neurons receive information about local motion cues from other brain regions, whereas the response of $\mathrm{CH}$ neurons is attributable to local motion cues arriving through dendro-dendritic electrical connections with HS neurons.

\section{Discussion}

The technique of photo-ablation makes it possible to assess the role of each tangential cell individually (Miller and Selverston, 1979). One concern with this technique, however, is whether laser illumination causes unspecific damage to neurons not injected with the fluorescent dye explicitly excited by the laser. We found that the responses of both unfilled neurons (data not shown) and neurons filled with Alexa 568 (Fig. 3) were not damaged by laser illumination. In addition, when $\mathrm{CH}$ cells were ablated, electrically connected HS cells continued to respond normally (Fig. 5). Warzecha et al. (1993) also found that neurons not filled with fluorescent dyes continued to function normally after laser illumination of the fly brain.

Using this technique, we have demonstrated that the response of $\mathrm{CH}$ cells to visual motion presented in front of the ipsilateral eye is entirely dependent on input from electrically coupled HS cells. In contrast, the response of HS cells turned out to be independent of input from $\mathrm{CH}$ cells. These two results provide convincing evidence that HS neurons receive local motion information directly from local motion elements and pass this information on to $\mathrm{CH}$ neurons (Figs. $1 B, 6$ ). Such a connection scheme has implications for understanding the visual response properties of $\mathrm{CH}$ cells, including their spatial integration properties, dendritic calcium signals during null direction motion stimuli, and the spatial blurring of motion signals on their dendrites.

The fact that input from HS cells, rather than direct input from local motion elements, drives $\mathrm{CH}$ cell activity provides an explanation for the spatial saturation properties found in these two neurons. The visual responses of $\mathrm{CH}$ and $\mathrm{HS}$ cells have been shown to saturate to the same degree with increasing spatial extent of the ipsilateral motion stimulus (Gauck and Borst, 1999; Haag et al., 1999). Because HS cells drive the $\mathrm{CH}$ cells, one would expect that as the HS cell response saturates so would the $\mathrm{CH}$ cell.

Another important aspect resolved by the current finding refers to the dendritic calcium measurements made in tangential cells. During null direction motion, an increase in calcium concentration has been observed in the small dendritic branches of ventral system (VS) cells (Borst and Single, 2000; Single and

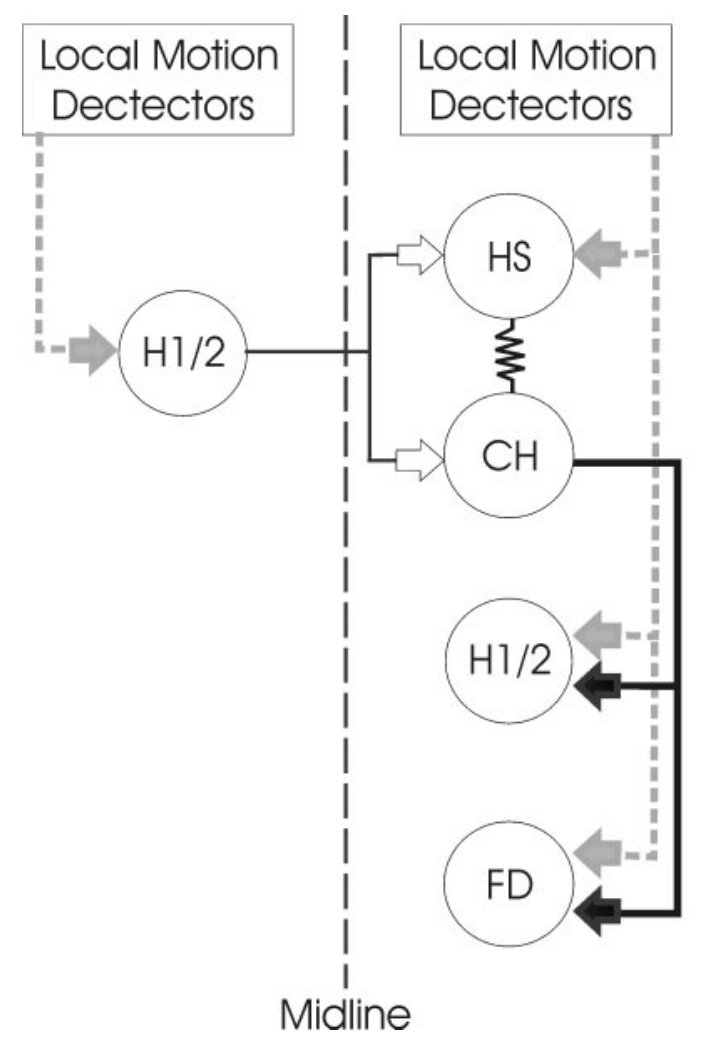

Figure 6. Schematic diagram of the input- output pathways of HS and CH cells. An array of local motion detectors supplies HS, H1, H2, and FD cells with local motion information (gray arrows). The PD for local motion input to $\mathrm{HS}$ and $\mathrm{FD}$ cells is front to back, whereas that of $\mathrm{H} 1$ and $\mathrm{H} 2$ cells is back to front. $\mathrm{HS}$ and $\mathrm{CH}$ cells are connected electrically via their dendritic trees. $\mathrm{CH}$ cells inhibit $\mathrm{H1}, \mathrm{H2}$, and FD cell GABAergic synapses (black arrows). In addition, $\mathrm{HS}$ and $\mathrm{CH}$ cells receive excitatory input (white arrows) from the contralateral $\mathrm{H} 1$ and $\mathrm{H} 2$ neurons. Solid lines indicate the known connectivity, and dashed lines indicate the assumed connections. The network is symmetric about the midline. Only one-half of the network is shown for clarity.

Borst, 2002) and HS cells (J. Haag and A. Borst, unpublished observations), but not CH cells (J. Haag, S. Single, and A. Borst, unpublished observations). This increase in calcium concentration during null direction stimuli has been assumed to be caused by the low directional selectivity of the excitatory input from local motion-sensitive elements, which presumably arrive on the dendrites via calcium-permeable nicotinic ACh receptors (Brotz and Borst, 1996; Oertner et al., 2001). Our findings explain why the dendritic calcium in $\mathrm{CH}$ cells does not rise during null direction stimulus, because ipsilateral motion information arrives via electrical coupling with HS cells and not via chemical synapses from motion-sensitive elements. It also points to a benefit of this type of connection scheme. The outputs of a $\mathrm{CH}$ cell are likely to be more directionally selective then, if it received direct input from local motion elements, because the calcium signal will follow the membrane potential more closely. The affect of presynaptic calcium levels of other tangential cells, VS cells, has been shown to be related linearly to presynaptic membrane depolarization and the firing rate of the postsynaptic V1 cell (Kurtz et al., 2001). Because local calcium concentrations trigger release at chemical synapses, the experiments of Kurtz et al. (2001) emphasizes the importance of having a calcium concentration near output synapses that conveys information reliably. The connection scheme found here would allow for dendritic calcium signals to follow the membrane potential and, thus, provide a well-tuned directionally selective output in $\mathrm{CH}$ cells. 
In addition, it has been demonstrated using calcium imaging techniques that the spatial representation of motion stimuli on the dendrites of $\mathrm{CH}$ cells is blurred relative to that of HS cell dendrites (Duerr and Egelhaaf, 1999; Haag and Borst, 2002). The input blueprint to the two neuronal types described above has been shown to be sufficient to account for the blurred visual image found in $\mathrm{CH}$ cells (Cuntz et al., 2003). It is likely that if $\mathrm{CH}$ cells also received direct input from local motion elements the relative blurring of the signals between $\mathrm{HS}$ and $\mathrm{CH}$ cells would be reduced.

A three neuron dendritic network has been proposed (Haag and Borst, 2002) to be important for the small-field tuning of a class of tangential cells called FD cells (Egelhaaf, 1985; Egelhaaf et al., 1993; Gauck and Borst, 1999; Kimmerle and Egelhaaf, 2000a; Haag and Borst, 2002). In this network, the HS-CH electrical coupling allows for the creation of a blurred retinotopic image on $\mathrm{CH}$ dendrites (Haag and Borst, 2002; Cuntz et al., 2003), whereas the GABAergic connection from $\mathrm{CH}$ onto FD cells mediates the subtraction of the original retinotopic signal, putatively present on FD cells, and the blurred signal arriving from $\mathrm{CH}$ cells (Warzecha et al., 1993). The connection scheme determined here (Fig. 6) demonstrates that the passing of motion information from the dendrites of $\mathrm{HS}$ to $\mathrm{CH}$ cells must be involved. However, when single HS neurons (HSE cells) were selectively ablated, the smallfield tuning of FD1 neurons was not affected (Warzecha et al., 1993). This might be a consequence of the large-field visual stimulus used in the experiments of Warzecha et al. (1993). FD1 cells are selectively activated by front-to-back small-field motion presented in the fronto-ventral part of ipsilateral visual space (Egelhaaf, 1985; Warzecha et al., 1993; Gauck and Borst, 1999; Kimmerle and Egelhaaf, 2000b). In addition, FD1 cells are inhibited by back-to-front motion presented in front of the contralateral eye (Egelhaaf, 1985; Gauck and Borst, 1999; Kimmerle and Egelhaaf, 2000a,b). To determine the small-field tuning of FD1 cells, Warzecha et al. (1993) compared the response of FD1 cells to a small-field stimulus presented in front of the ipsilateral eye with a stimulus that mimicked large-field rotation. This stimulus consisted of an extended background moving from front to back on the ipsilateral side and from back to front on the contralateral side. $\mathrm{vCH}$ cells receive excitatory input about back-to-front motion presented in front of the contralateral eye via spiking neurons ( $\mathrm{H} 1$ and $\mathrm{H} 2$ cells) that synapse directly on $\mathrm{CH}$ cells (Hausen, 1981; Eckert and Dvorak, 1983; Gauck et al., 1997). Hence, the killing of an HSE cell would not eliminate the activity of a $\mathrm{vCH}$ cell when contralateral motion is presented. In addition, when ipsilateral stimuli are used, the area of a $\mathrm{CH}$ cell dendritic tree that is excited depends on the elevation at which the stimulus is presented (Egelhaaf et al., 1993; Duerr and Egelhaaf, 1999; Haag and Borst, 2002). The top visual-field stimulus will excite the more dorsal dendrites, whereas the bottom visual stimulus will stimulate the ventral dendrites. HSE and HSS cells are known to selectively activate the dorsal and ventral halves of the vCH cell dendritic tree, respectively (Haag and Borst, 2002). This implies that, after the ablation of a single HS cell, it is important to restrict the stimulus to the receptive field of this cell for the effect to become visible. Taken together, the missing effect of HS cell ablation on the small-field tuning of FD cells reported by Warzecha et al. (1993) can be fully explained by the large-field stimulus used in their study. This stimulus is sufficient to activate the $\mathrm{vCH}$ cell through the contralateral $\mathrm{H} 1$ and $\mathrm{H} 2$ cells, as well as via the remaining ipsilateral HS cells.

The dendritic tree of $\mathrm{CH}$ cells has more than one output target. In addition to FD cells, $\mathrm{CH}$ neurons have been shown to influence the activity of other tangential cells, including $\mathrm{H} 1$ and $\mathrm{H} 2$ cells (Haag and Borst, 2001). H1 and H2 cells are large-field motion-sensitive neurons that respond in a directionally selective way. Both cells respond best to PD stimuli moving from front to back. These connections appear to affect the selectivity of these neurons to rotational flow fields.

In future experiments, we will investigate the functions of these different dendritic networks using the laser ablation techniques described here. In doing so, we hope to detail the different computational capabilities of $\mathrm{CH}$ neurons and relevant dendritic networks, in relation to the various input-output pathways. These experiments, with modeling studies, will give additional insight into the functional relevance of the dendritic electrical coupling of $\mathrm{HS}$ and $\mathrm{CH}$ cells.

\section{References}

Borst A, Egelhaaf M (1992) In vivo imaging of calcium accumulation in fly interneurons as elicited by visual motion stimulation. Proc Natl Acad Sci USA 89:4139-4143.

Borst A, Haag J (1996) The intrinsic electrophysiological characteristics of fly lobula plate tangential cells: I. Passive membrane properties. J Comput Neurosci 3:313-336.

Borst A, Haag J (2002) Neural networks in the cockpit of the fly. J Comp Physiol [A] 188:419-437.

Borst A, Single S (2000) Local current spread in electrically compact neurons of the fly. Neurosci Lett 285:123-126.

Borst A, Egelhaaf M, Haag J (1995) Mechanisms of dendritic integration underlying gain control in fly motion-sensitive interneurons. J Comput Neurosci 2:5-18.

Brotz TM, Borst A (1996) Cholinergic and GABAergic receptors on fly tangential cells and their role in visual motion detection. J Neurophysiol 76:1786-1799.

Cuntz H, Haag J, Borst A (2003) Neural image processing by dendritic networks. Proc Natl Acad Sci USA 100:11082-11085.

Duerr V, Egelhaaf M (1999) In vivo calcium accumulation in presynaptic and postsynaptic dendrites of visual interneurons. J Neurophysiol 82:3327-3338.

Eckert H, Dvorak DR (1983) The centrifugal horizontal cells in the lobula plate of the blowfly Phaenicia sericata. J Insect Physiol 29:547-560.

Egelhaaf M (1985) On the neuronal basis of figure-ground discrimination by relative motion in the visual system of the fly. II. Figure-detection cells, a new class of visual interneurones. Biol Cybern 52:195-209.

Egelhaaf M, Borst A, Reichardt W (1989) Computational structure of a biological motion detection-detection system as revealed by local detector analysis in the fly's nervous system. J Opt Soc Am A 6:1070-1087.

Egelhaaf M, Borst A, Warzecha AK, Flecks S, Wildemann A (1993) Neural circuit tuning fly visual neurons to motion of small objects II. Input organization of inhibitory circuit elements revealed by electrophysiological and optical recording techniques. J Neurophysiol 69:340-351.

Gauck V, Borst A (1999) Spatial response properties of contralateral inhibited lobula plate tangential cells in the fly visual system. J Comp Neurol 406:51-71.

Gauck V, Egelhaaf M, Borst A (1997) Synapse distribution on VCH, an inhibitory, motion-sensitive interneuron in the fly visual system. J Comp Neurol 381:489-499.

Geiger G, Nässel DR (1981) Visual orientation behavior of flies after selective laser beam ablation of interneurones. Nature 293:398-399.

Haag J, Borst A (1996) Amplification of high-frequency synaptic inputs by active dendritic membrane processes. Nature 379:639-641.

Haag J, Borst A (2001) Recurrent network interactions underlying flowfield selectivity of visual interneurons. J Neurosci 21:5685-5692.

Haag J, Borst A (2002) Dendro-dendritic interactions between motionsensitive large-field neurons in the fly. J Neurosci 22:3227-3233.

Haag J, Borst A (2003) Orientation tuning of motion-sensitive neurons shaped by vertical-horizontal network interactions. J Comp Physiol [A] 189:363-370.

Haag J, Vermeulen A, Borst A (1999) The intrinsic electrophysiological characteristics of fly lobula plate tangential cells: III. Visual response properties. J Comput Neurosci 7:213-234. 
Hausen K (1981) Monocular and binocular computation of motion in the lobula plate of the fly. Verh Dtsch Zool Ges 74:49-70.

Hausen K (1982) Motion sensitive interneurons in the optomotor system of the fly. I. The horizontal cells: structure and signals. Biol Cybern 45:143-156.

Hausen K (1984) The lobula-complex of the fly: structure, function and significance in visual behaviour. In: Photoreception and vision in invertebrates (Ali MA, ed), pp 523-559. New York, London: Plenum.

Hausen K, Wehrhahn C (1990) Neural circuits mediating visual flight control in flies. II. Separation of two control systems by microsurgical brain lesions. J Neurosci 10:351-360.

Hausen K, Wolburg-Buchholz K, Ribi WA (1980) The synaptic organization of visual interneurons in the lobula complex of flies. Cell Tissue Res 208:371-387.

Heisenberg M, Wonneberger R, Wolf R (1978) Optomotor-blind (H31) —a Drosophila mutant of the lobula plate giant neurons. J Comp Physiol [A] 124:287-296.

Hengstenberg R (1977) Spike response of "non-spiking” visual interneurone. Nature 270:338-340.

Hengstenberg R, Hausen K, Hengstenberg B (1982) The number and structure of giant vertical cells (VS) in the lobula plate of the blowfly Calliphora erytrocephala. J Comp Physiol [A] 149:163-177.

Jacobs GA, Miller JP (1985) Functional properties of individual neuronal branches isolated in situ by laser photoinactivation. Science 228:344-346.

Kimmerle B, Egelhaaf M (2000a) Detection of object motion by a fly neuron during simulated flight. J Comp Physiol [A] 186:21-31.

Kimmerle B, Egelhaaf M (2000b) Performance of fly visual interneurons during object fixation. J Neurosci 20:6256-6266.

Krapp HG, Hengstenberg R (1996) Estimation of self-motion by optic flow processing in single visual interneurons. Nature 384:463-466.

Krapp HG, Hengstenberg B, Hengstenberg R (1998) Dendritic structure and receptive-field organization of optic flow processing interneurons in the fly. J Neurophysiol 79:1902-1917.

Kurtz R, Warzecha AK, Egelhaaf M (2001) Transfer of visual motion information via graded synapses operates linearly in the natural activity range. J Neurosci 21:6957-6966.

Meyer EP, Matute C, Streit P, Nassel DR (1986) Insect optic lobe neurons identifiable with monoclonal antibodies to GABA. Histochemistry 84:207-216.

Miller JP, Selverston A (1979) Rapid killing of single neurons by irradiation of intracellularly injected dye. Science 206:702-704.

Oertner TG, Brotz TM, Borst A (2001) Mechanisms of dendritic calcium signaling in fly neurons. J Neurophysiol 85:439-447.

Selverston AI, Miller JP (1980) Mechanisms underlying pattern generation in lobster stomatogastric ganglion as determined by selective inactivation of identified neurons. I. Pyloric system. J Neurophysiol 44:1102-1121.

Selverston AI, Kleindienst H-U, Huber F (1985) Synaptic connectivity between cricket auditory interneurons as studied by selective photoinactivation. J Neurosci 5:1283-1292.

Single S, Borst A (1998) Dendritic integration and its role in computing image velocity. Science 281:1848-1850.

Single S, Borst A (2002) Different mechanisms of calcium entry within different dendritic compartments. J Neurophysiol 87:1616-1624.

Single S, Haag J, Borst A (1997) Dendritic computation of direction selectivity and gain control in visual interneurons. J Neurosci 17:6023-6030.

Strausfeld NJ, Lee JK (1991) Neuronal basis for parallel visual processing in the fly. Vis Neurosci 7:13-33.

Warzecha AK, Egelhaaf M, Borst A (1993) Neural circuit tuning fly visual interneurons to motion of small objects. I. Dissection of the circuit by pharmacological and photoinactivation techniques. J Neurophysiol 69: 329-339. 